www.jmscr.igmpublication.org

Impact Factor 6.379

Index Copernicus Value: 71.58

ISSN (e)-2347-176x ISSN (p) 2455-0450

crossref DOI:_https://dx.doi.org/10.18535/jmscr/v6i3.204

\title{
Type 1 Diabetes mellitus and Neurofibromatosis 1 : A Rare Association (Case report)
}

\author{
Authors \\ Mohamed Amin Gebreel MD ${ }^{1}$, Amira Ali ZaakokMD², Hazem Mohamed Skr MSC \\ Mohamed Elsayed Abudagher MSC ${ }^{4}$, Ameer Sobhi Eldeep MSC \\ ${ }^{1}$ Lecturer of Pediatrics, Faculty of medicine, Al Azhar University, Cairo, Egypt \\ ${ }^{2}$ Consultant Dermatology ,Faculty of medicine, AlAzhar University, Cairo, Egypt \\ ${ }^{3}$ Specialist Dermatology ,Faculty of medicine, AlAzhar University, Cairo, Egypt \\ ${ }^{4}$ Pediatric Endocrinology Specialist, IBN SINA College Hospital, Jeddah, Saudi Arabia. \\ ${ }^{5}$ Pediatric Neurology Specialist, IBN SINA College Hospital, Jeddah, Saudi Arabia. \\ Corresponding Author \\ Mohamed Amin Gebreel MD ${ }^{1}$ \\ Email:mohamedgebreel37@gmail.com,meiiiaa@yahoo.com,hazemskr@yahoo.com,
} dr.dagher87y@yahoo.com,ameer.eldeep@mail.com

\begin{abstract}
Neurofibromatosis type 1 is a genetic disorder with abnormalities of the nervous tissue, bones, skin and soft tissues.It allows the growth of tumors along the nerves of bone, skin and brain. It is rarely associated with diabetes mellitus. We reported a case with neurofibromatosis type 1 and type 1 diabetes mellitus.

Keywords: Neurofibromatosis type 1 .diabetes mellitus
\end{abstract}

\section{Introduction}

Neurofibromatosis type $1(\mathrm{NF} 1)$ is a genetic relatively common disorder characterized by changes in skin color and the growth of tumors on the nerves of the skin, brain, bone and other body parts . Its severity as well as specific features varies from one individual to another. ${ }^{(1)}$ It belongs to a group of related genetic conditions called the RAS opathies caused by mutations in genes of the Ras-MAPK pathway leading to profound effects on growth and development. ${ }^{(2)}$ It is caused by mutations in the NF 1 gene and is inherited as an autosomal dominant manner. In about $50 \%$ of cases, it is inherited from an affected parent. Other cases result from a new mutation, with no family history of NF1. ${ }^{(3)}$

NF1 occurs with an estimated incidence of 1 : 2,500 - 3,000 individuals independent of ethnicity, gender or race. ${ }^{(4)}$ Von Recklinghausen was the first one who described it in 1882, but clinical diagnostic criteria were established in 1987 and revised in 1997 by the National Institutes of Health Consensus Development Conference. ${ }^{(5)}$ Patients with NF1 show an increased incidence of tumors arising from neural crest such as neuro fibromas, Leiomyomas and 
ganglio neuromas. It has been also related to small bowel adenocarcinoma, as well as pancreatic endocrine malignant tumors. ${ }^{(6)}$

The diagnosis of NF1 is made if two or more of the following criteria present :[1]Six or more caféaulait spots more than $5 \mathrm{~mm}$ in the greatest diameter in prepubertal individuals[2],two or more neuro fibroma of any type or one plexi form neuro fibroma,[3]axillary or inguinal freckling,[4] bone abnormalities including sphenoid dysplasia or tibial pseudarthrosis,[5] two or more Lisch nodules, [6] Optic glioma, or[7] a parent, sibling, or child who had NF1. ${ }^{(7)}$

\section{Case Report}

A 5-year-old girl was admitted to the department of pediatrics of Ibn Sina College General Hospital, Jedda ,Saudi Arabia, with a history of fever, vomiting with abdominal pain, and disturbed level of consciousness .She was the second kid of consanguineous parents. Her perinatal history was uneventful. Family history for NF1 was positive for her brother. By examination, weight was $13 \mathrm{~kg}$ (below5 ${ }^{\mathrm{pe}}$ rcentile), height was $110 \mathrm{~cm}$ (below $5^{\text {th }}$ percentile), head circumference $50 \mathrm{~cm}$, blood pressure was normal and pulse rate was 120 bum She was presented by diabetic ketoacidosis with urgent treatment in PICU by intravenous fluids and insulin. Skin examination revealed multiple (10) more than $5 \mathrm{~mm}$ café-au-laitpatches in the upper limb, back, trunk and face (which is unusual site for the spots) varied in size the largest one is $7.8 \mathrm{~mm}$. One of these patches is hairy $5.5 \mathrm{~mm}$ india meter. There was axillary freckling on both sides. In addition, there was soft non tender hepatomegaly (12 cm span).

Laboratory investigations revealed a blood glucose level of $540 \mathrm{mg} / \mathrm{ld}$.;HbA1c10.7\% with glycosuria and ketonuria. Severe metabolic acidosis was present;ph7.06 Paco2 $15.5 \mathrm{mmHg}$, HCO $7.9 \mathrm{mmol} / \mathrm{l}$. Liver, renal ,thyroid function tests as well as serum electrolytes were normal. The patient was diagnosed with NF1 and type 1diabetes mellitus. Insulin treatment was started with intravenous fluids for 3 days. She was firstly diagnosed as diabetic at that time. Abdominal ultrasound and MRI were normal.

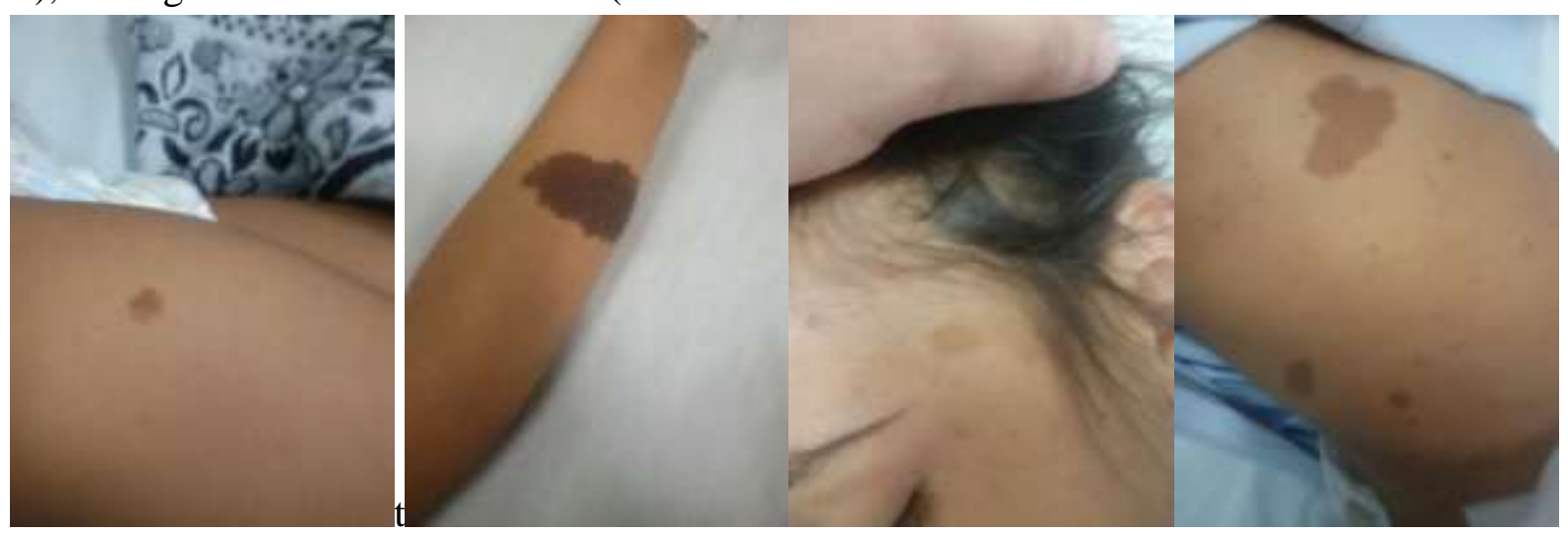

Figure 1: multiplecafé-au-lait patches more than $5 \mathrm{~mm}$ in the upper limb and face vary in size the largest one is $7.8 \mathrm{~mm}$. One of them is hairy with $5.5 \mathrm{~mm}$ in diameter.

\section{Discussion}

NF1 gene is mapped to chromosome 17q11.2. $50 \%$ of the patients are due to de novo gene mutation (8).We diagnosed our case by finding 10 café-au-lait spots more than $5 \mathrm{~mm}$ in the greatest diameter with axillary freckling in both sides in addition; there was positive family history in her brother. No other clinical features of $\mathrm{NF}$, antibodies or somatostatinoma were detected.
Only few reports clarify the association between NF1 and other autoimmune diseases as systemic lupus erythromatosus, mixed connective tissue disease, rheumatoid arthritis, glomerulo nephritis, aswell as bullous pemphigoid and vitiligo. ${ }^{(5,9)}$ Diabetes mellitus is rarely seen in children with NF1. It is attributed to the presence of duodenal somatostatinoma ${ }^{(10)}$ which is a very rare neuroendocrine tumor(1:40 million )arises 
from the pancreas or the gastrointestinal tract ${ }^{(12)}$ .It is characterized by excessive secretion of somatostatin hormone by tumor cells of D-cell origin and associated with diabetes mellitus(95\%) ,gall stone, weight loss, steatorrhea and achlorhydria. ${ }^{(13,14)}$ Only one case of duodenal somatostatinoma reported in a patient with NF1 removed by open local excision. ${ }^{(11)}$ Only 3 children with diabetes mellitus associated with NF1 cases have been reported. The first case reported by Zaka-ur-Rab and Chopra. ${ }^{(10)}$ in 9-yearold boy known to have NF1 since birth and diabetes mellitus. The second case was reported by Kamoun et al. ${ }^{(15)}$ in 15 -year-old boy with positive family history for $\mathrm{NF} 1$, and positive glutamic acid decarboxylase (GAD) antibodies only. The third case reported byOzhan al $2013^{(6)}$ in a 9 year old boy without finding of antibodies or soamtostatinoma.

\section{Conclusion}

Association of NF 1 and diabetes mellitus is not only very rare but also unexplained till now. This raises the necessity for proper identification of possible pancreatic antibodies to help for accurate diagnosis. Furthermore, new diagnostic modalitiesare essential forearly detection of duodenal carcinoid or somatostatinoma.

\section{Declaration of Conflicting Interest}

The authors declare that they have no competing interests.

\section{Funding}

Funding was not received from another sources.

\section{Refrences}

1. Friedman JM. Neurofibromatosis 1. 1998 Oct 2 [updated 2014 Sep 4]. In: Pagon RA, Adam MP, Ardinger HH, Wallace SE, Amemiya A, Bean LJH, Bird TD, Ledbetter N, Mefford HC, Smith RJH, Stephens K, editors. GeneReviews ${ }^{\circledR}$ [Internet]. Seattle (WA): 1993-2017. http://www.ncbi.nlm.nih.gov/books/NBK1 109/ Citation on PubMed
2. Rauen $\mathrm{K}$.The RASopathies. Annu Rev Genomics Hum Genet2013;14:355-69. doi: 10.1146/annurev-genom-091212153523.

3. Hsieh DT. Neurofibromatosis Type 1. Medscape Reference. July 27, 2016; http://emedicine.medscape.com/artic le/1177266-overview.

4. Abbas A. Disease caused by immune responses: hypersensitivity and autoimmunity. In: Abbas A, Lichtman H, editors. Cellular and molecular immunology.5th edition. Philadelphia: Saunders; 2005. p. 411 -31

5. Williams V, Lucas j,Babcock M, Gutmann D ,Bruce B,MariaB."Neurofibromatosis type 1 revisited,'Pediatrics.2009; Jan;123(1):124-33. https://doi.org/10.1542/peds.2007-3204

6. Ozhan B,Ozguven A,Ersoy B.Neurofibromatosis Type 1 and Diabetes Mellitus:Case Reports in Endocrinology Volume 2013, Article ID 689107, 3 pages.

7. KorfB.Neurofibromatosis type 1 (NF1): Pathogenesis, clinical features and diagnosis. UpToDate.June 2015; Accessed 7/19/2015.

8. Jett K, Friedman J. Clinical and Genetic Aspects of Neurofibromatosis 1. Genetics in Medicine, Genet Med. 2010: Jan;12(1): 1-

11https://doi.org/10.1097/GIM.0b013e318 $1 \mathrm{bf} 15 \mathrm{e} 3$

9. TekinF,CarcurganS,IlterT.“Autoimmuneha emolysis as an unusual cause of anaemia in von Recklinghausen's disease,"Neth J Med. 2004 Oct;62(9):337-9.

10. Zaka-ur-Rab Z ,Chopra K. "Diabetes mellitus in neurofibromatosis I:an unusual presentation,'Indian Pediatrics, (2005) ;42,:185-6

11. Bhandari R, RiddioughG, Lokan J, Weinberg, L,Efthymiou M, Nikfarjam M. Somatostatinoma of the minor papilla treated by local excision in a patient with neurofibromatosis type 1. JOP.2015;Jan 
31.16(1):81-4.doi:10.6092/1590-

$8577 / 2906$

12. Williamson, J, Thorn C, Spalding, D,

Williamson, C. Pancreatic and

Peripancreatics omatostatinomas.

Ann R Coll Surg Engl. 2011 Jul. 93(5):356-60.

13. Ellison T, Edil B. The current management of pancreatic neuroendocrine tumors. Adv Surg. 2012; 46:283-96.

14. YeoJ. Neoplasms of the endocrine pancreas. Greenfield J, Mulholland W, OldhamT, eds. Surgery: Scientific Principles and Practice. 3rd ed. Philadelphia, Pa: Lippincott Williams \& Wilkins; 2001; 899-13.

15. Kamoun, M., Charfi N., Rekik ,N., "Neurofibromatosis and type 1 diabetes mellitus: an unusual association: letters: original observations," 2009; Diabetic Medicine,( 26)1180-1. 